

\section{ASSESSING THE CREDIBILITY OF THE CALORIFIC VALUE OF MUNICIPAL SOLID WASTE}

K. L. Churney, E. S. Domalski, A. E. Ledford, J. C. Colbert,

S. S. Bruce, T. J. Buckley, R. C. Paule*, and M. L. Reilly**

U.S. DEPARTMENT OF COMMERCE

National Bureau of Standards

Chemical Thermodynamics Division

Center for Chemical Physics

and the

National Measurement Laboratory*

and the

Temperature and Pressure Division**

Center for Basic Standards

Washington, DC 20234

February 1984

Prepared for

U.S. Department of Energy

Office of Renewable Technology

Energy from Municipal Waste Division

Forrestal Building

1000 Independence Avenue, SW

Washington, DC 20585

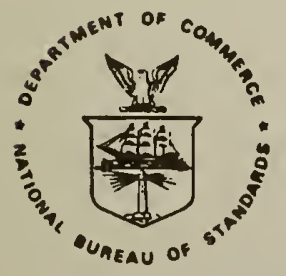

U.S. DEPARTMENT OF COMMERCE, Malcolm Baldrige, Secretary NATIONAL BUREAU OF STANDARDS, Ernest Ambler, Director 



\section{Assessing the Credibility of the Calorific Value of Municipal Solid Waste}

K.L. Churney, E.S. Domalski, A.E. Ledford, J.C. Colbert, S.S. Bruce, T.J. Buckley,

\section{Chemical Thermodynamics Division}

Center for Chemical Physics

R. C. Paule,

National Measurement Laboratory

and

M.L. Reilly

Temperature and Pressure Division

Center for Basic Standards

National Bureau of Standards

Washington, D.C. 20234 


\section{PREFACE}

Th1s report gives the results of studies which were started in fiscal year 1981, continued through 11scal year 1982, and were completed in fiscal year 1983. Two important industr1al/municipal queries required response in this study. In response to the 11rst, we compared the preclaton and accuracy of the calorific value of municipal solid waste (MSW) which had been processed to 2 particle size or less and which had been burned in both a gram-size bomb calorimeter and in the kilogram-size flow calorimeter. In response to the second query, we determined whether there would be a significant difference between the results of burning an unprocessed and processed MSW sample in the kilogram-capacity combustion flow calorimeter. The results of the calorimetric studies which respond to these querles are presented in this report.

The chronology of progress in this study was as follows:

Oct 80 - Feb 81 Design of kilogram capacity flow calorimeter.

Feb 81 - Apr 81 Critique and development of engineering drawings.

Apr 81 - Jun 81 Competitive bldding.

Jun 81 - Jul $81^{\circ}$ Awarding of b1d to vendors.

JuI 81 - Feb. 82 Fabrication period.

Feb 82 - Apr 82 Assembly.

Apr 82 - Dec 82 Preliminary testing, combustion runs (First combustion May 82).

Jan 1983

Baltimore County Sampling. 
Feb 83

Feb 82 - May 83

Apr 83 - Oct 83

Sep 13, 1983

Sep $83-$ Oct 83
Development of Measurement Protocol

(Statistically designed experiments).

Construction and completion of product gas analysis train.

Calorimetric Measurements. (A total of 26 calorimetric experiments were carried out).

DoE Research Review on the Characterization of Municipal Solid Waste.

Calculation of Results. 
Abstract

1. Introduction

2. Experimental Apparatus

2.1 Description of $2.5 \mathrm{Kg}$ Flow Calorimeter and Auxiliary Apparatus _ 5

2.2 Description of a Typical Experiment 10

3. Sample Preparation and Measurement Protocol 15

4. Experimental Results 22

4. 1 Combustion Bomb Calorimetry 22

4.2 Combustion Flow Calorimetry 27

4.2.1 Flow Calorimetry of RDF-4 27

4.2.2 Flow Calorimetry of RDF-2 32

4.3 Summary of Statistical Results 35

5. Discussion and Conclusions 36

6. References 39

7. Acknowledgements 40 


\section{List of Tables}

Page

Table 1. Specifications for the $2.5 \mathrm{~kg}$ capacity flow calorimeter. 8

Table 2. Composition of municipal solid waste obtained Jan 10-21, 1983, from the Baltimore County Resource and Recovery Facility. 17

Table 3. Measurement protocol. 19

Table 4. Ash and combustion bomb calorimetry results for two-gram test samples. 23

Table 5. Summary of statistical analysis of ash and combustion bomb calorimetry results for two-gram test samples. 25

Table 6. Flow and bomb calorimetry results on processed MSW (RDF-4). 28

Table 7. Mass Fractions of Bags $E$ and $E^{\prime}$ contributed by Bags $C$ and $D$. 29

Table 8. Analysis of flow and bomb calorimetry results on processed MSW (RDF-4). 30

Table 9. Flow calorimetry results on unprocessed and processed MSW. 33

Table 10. Analysis of flow calorimetry results on kilogram-size samples of processed and unprocessed MSW. 


\section{List of Figures}

Figure 1. Diagram of the $2.5 \mathrm{~kg}$ capacity flow calorimeter. 7

Figure 2. A plot of the concentrations of gaseous carbon dioxide, water, and carbon monoxide as a function of time for a typical experiment on RDF. 12

Figure 3. A plot of the temperature rise of the calorimeter water plus the deviation of the observed data points from the smooth curve fit to the data during the drift periods. 14

Figure 4. Diagram of the sample division technique used to prepare gram-size test samples (C and D) for the bomb calorimeter studies and kllogram-size samples ( $E$ and $E^{\prime}$ ) for the flow calorimeter studies from $2.5 \mathrm{kilogram}$ hand sorted and reconstituted samples in bags $C$ and $D$. 
ASSESSING THE CREDIBILITY OF THE CALORIFIC VALUE OF MUNICIPAL SOLID WASTE

K.L. Churney, E.S. Domalski, A.E. Ledford, J.C. Colbert,S.S. Bruce, T.J. Buckley, R. C. Paule, and M.L. Reilly

\section{Abstract}

A study has been made at the National Bureau of Standards to establish the limits of reliability of the calorific value of municipal solid waste (MSW) determined by the bomb calorimetric procedure currently used in commercial test laboratories. This procedure involves using gram-size samples derived from MSW that has been processed down to a particle size of $2 \mathrm{~mm}$ or less. Critics of the procedure argue that gram-size samples are too small to be representative of such a large quantity of so heterogeneous a material, and that processing MSW may also alter its composition.

To test the bomb calorimetric procedure, a $2.5 \mathrm{~kg}$ capacity combustion flow calorimeter was designed and constructed for the determination of the enthalpies of combustion of kilogram-size samples of MSW in flowing oxygen near atmospheric pressure.

Calorimetric data on processed MSW were obtained using both the kilogramsize flow and a gram-size bomb calorimeter. Intercomparison of results shows that the calorific value (on a dry basis) of gram-size test samples agrees, within the uncertainty of our experiments, with the corresponding values for their kilogram-size parent samples provided that the sample division technique used to obtain the gram-size samples is that described in this work. The average difference of the parent minus gram-size sample values (on a dry basis) 
is -0.18 with an imprecision ( $95 \%$ confidence interval) of \pm 1.18 of the mean caloriflc value.

The effects of processing on sample composition were determined by intercomparison of flow calorimetric results on kilogram-size samples of processed and minimally processed MSW ( $150 \mathrm{~mm}$ or less particle size) that are nominally identical. The average difference of the unprocessed minus processed values (on a dry basis) is $-0.5 \%$ with an imprecision ( $95 \%$ confidence interval) of $\pm 2.9 \%$ of the mean calorific value.

\section{Introduction}

The work described in this paper was performed to assist in resolving an industrial problem formulated by members of the ASME Research Committee on Industrial and Municipal Wastes, the ASME Performance Test Code Committee (PTC33) on Large Incinerators, and the ASTM Committee (E-38) on Resource Recovery. Incinerator-boiler systems which are used to dispose of municipal solid waste (MSW) are bought and sold on the basis of thermal specifications. To determine whether a system meets its thermal specifications, the calorific value of the input waste stream fed to the system must be known. At present, the calorific value is determined at commercial test laboratories using gram-size samples of the waste.

It has been the opinion of many combustion engineers that one cannot accurately sample a large, multiton quantity of MSW down to one or two grams and obtain a representative test sample. The calorific value determined from such a small sample would be suspect. Gram-size samples must be prepared from the bulk MSW by separation and milling techniques to provide a powdered test sample of approximately $2 \mathrm{~mm}$ or less particle size. Many combustion engineers feel that this processing may significantly alter the composition of the test sample and, hence, the calorific value. This might occur because of changes in composition 
due to excessive local heating associated with some milling operations or due to sampling and handling a material which is inhomogeneous and segregates easily.

The general question of whether or not the calorific value of a multiton quantity of MSW can be obtained by sampling down to one or two grams can be broken into two parts. The first part 1s: How should one sample a multiton pile or stream of raw waste in order to obtain inorements of sufficient number and size to characterize the calorific value with a given precision? The second part is: How can one obtain representative gram-size samples that characterize these increments? The various issues in the dispute about the validity of the current method for determining the calorific value of MSW are primarily concerned with the second of these questions.

To address these 1ssues, the National Bureau of Standards (NBS) Initiated a research program in collaboration with the U.S. Department of Energy to develop test procedures for accurately determining the calorific values of refuse and refuse-derived fuels (RDF). This research also was part of the NBS response to the Resource Conservation and Recovery Act of 1976. Subtitle $\mathrm{E}$ of this legislation mandated NBS to provide guidelines for the development of specifications for classification of materials destined for disposal.

NBS made a commitment to develop a calorimeter to accommodate a sample of MSW which is larger than that currently used in commercial test laboratories. In addition the MSW sample should be processed as little as possible. After many discussions with combustion engineers and statisticians, we decided that an acceptable sample size was about $2.5 \mathrm{~kg}$ and that the sample would be derived from dried $\mathrm{RDF}_{-2}{ }^{(+)}$. In terms of the general sampling question, cited

(+) RDF-2 is MSW that has been processed to reduce the particle size so that 95 mass-percent passes through a $15 \mathrm{~cm}$ square mesh screen. 
previously, the sample s1ze adopted for the calorimeter is assumed to be a convenient fraction of a sampling lncrement for the waste stream.

For safety considerations, we chose to bulld a calorimeter for the combustion of samples in flowing oxygen near atmospher10 pressure rather than to scale up the convent1onal h1gh pressure oxygen combustion bomb. After the $1880^{\prime}$, the development of the flow technique was discontinued in favor of the simpler procedures and more quantitative results which could be obtained with the bomb calorimeter. As a consequence, the first goal of this project was to demonstrate that the oxygen flow technique could be used to obtain complete combustion of MSW.

To test the oxygen flow technique, a combustion flow calorimeter $[1,2]$ was built and used to successfully combust 258 pellets of RDF- ${ }^{(+)}$. Combustion of RDF which has been compressed into a pellet rather than left in loose form was adopted because this configuration simplifies quantitative collection of ash and prevents dispersion of the sample away from the main reaction zone. The amount of carbon in the ash and the uncertainty in the amount of $\mathrm{CO}$ in the combustion products contributed errors of less than $0.1 \%$ to the enthalpy of combustion.

After an initial study of the variability of MSW was carried out at NBS in 1980 [3], it was concluded that a calorimeter which could burn a kilogram-size sample with a total uncertainty of less than one percent in the enthalpy of combustion would satisfy our requirements.

Prior to designing a large-scale combustion flow calorimeter, the burning characteristics of kilogram-size pellets of RDF-2 in oxygen were determined [4].

(+) RDF-4 is MSW from which the metal has been removed and then processed to reduce the particle s1ze so that 95 mass-percent passes through a $2 \mathrm{~mm}$ square mesh screen. 
The burning characteristics were unknown and were expected to be different from RDF-4. The physical heterogeneity, measured against sample size, and variability of composition of RDF-2 pellets are greater than those of RDF-4 pellets. The goal of these experiments was to develop a method of controlled burning of a 2 to $2.5 \mathrm{~kg}$ pellet at a rate of 15 minutes or less per kilogram. This time limit was the estimated maximum time which could guarantee that the imprecision contributed by the calorimetric measurement would be less than one percent.

A series of eighteen trial experiments were carried out in a prototype combustor [4]. Burning times of $15 \mathrm{~min} / \mathrm{kg}$ for RDF-2 were obtained using the following measures. The sample was enclosed by a crucible to reduce heat loss. A small, secondary, flow of oxygen in the form of horizontal jets of preheated oxygen was directed at the sides of the cylindrical pellet. The larger, primary, oxygen flow was supplied as a diffuse flow that was directed at the bottom of the sample.

After developing a suitable technique for burning a kilogram-size sample of RDF-2, a $2.5 \mathrm{~kg}$ capacity flow calorimeter was designed, fabricated, and placed in operation. Calorimetric measurements have been carried out in a study consisting of 26 experiments designed to resolve part of the dispute about the current method of determining the calorific value of MSW. A brief description of the calorimeter, auxiliary measurement equipment, and the main features of a typical experiment is given in section 2. The measurement protocol is discussed in section 3. Results are analyzed in section 4. Conclusions are given in section 5 .

\section{Experimental Apparatus}

\subsection{Description of $2.5 \mathrm{Kg}$ Flow Calorimeter and Auxiliary Apparatus}

The flow calorimeter consists of two basic parts: a constant temperature jacket and the calorimeter proper. The latter contains the sample combustor. 
Heat 11 berated in the combustion reaction is transferred to the stirred water in the calorimeter vessel, the outermost container of the calorimeter proper. The rise in temperature of the calorimeter water, after correction for heat exchange w1th the jacket and for heat transport by the flowing gases, is proportional to the enthalpy of combustion of the sample. The calorimeter is calibrated by determining the temperature rise produced by combustion of a known mass of microcrystalline cellulose whose enthalpy of combustion has been established by bomb calorimetry.

A cross section of the flow calorimeter is shown in Figure 1. The important dimensions and calorimeter properties are listed in Table 1. All metal components were fabricated from type 316 stainless steel.

The cylindrical compressed sample pellet (nominally $23 \mathrm{~cm}$ diameter and $15 \mathrm{~cm}$ high), A, is located inside and near the bottom of the combustor, B. The pellet is supported on a horizontal lattice of nine alumina rods (6 mm diameter) resting in notches cut in the top edge of a cup-shaped ash pan. The ash pan sits on the access plate that forms the bottom of the combustor and retains the residual ash from the burned MSW. An iron fuse wire, having a four turn coil touching the top of the sample at the center, is stretched horizontally between two electrodes (shown on either side of the sample in Figure 1). The sample is ignited by passage of electrical current through the fuse wire.

Flowing oxygen is supplied to the sample by an array of nozzles arranged in five horizontal tiers. Each tier contains six symmetrically spaced nozzles located in the combustor wall. The bottom tier supplies oxygen through slots in the ash pan to form a diffuse stream that is directed at the bottom of the sample. The other tiers supply narrow jets of oxygen that are either directed at the sides of the sample or into the space above the sample. The oxygen of the top four tiers is preheated by passing it through colls wound around and 


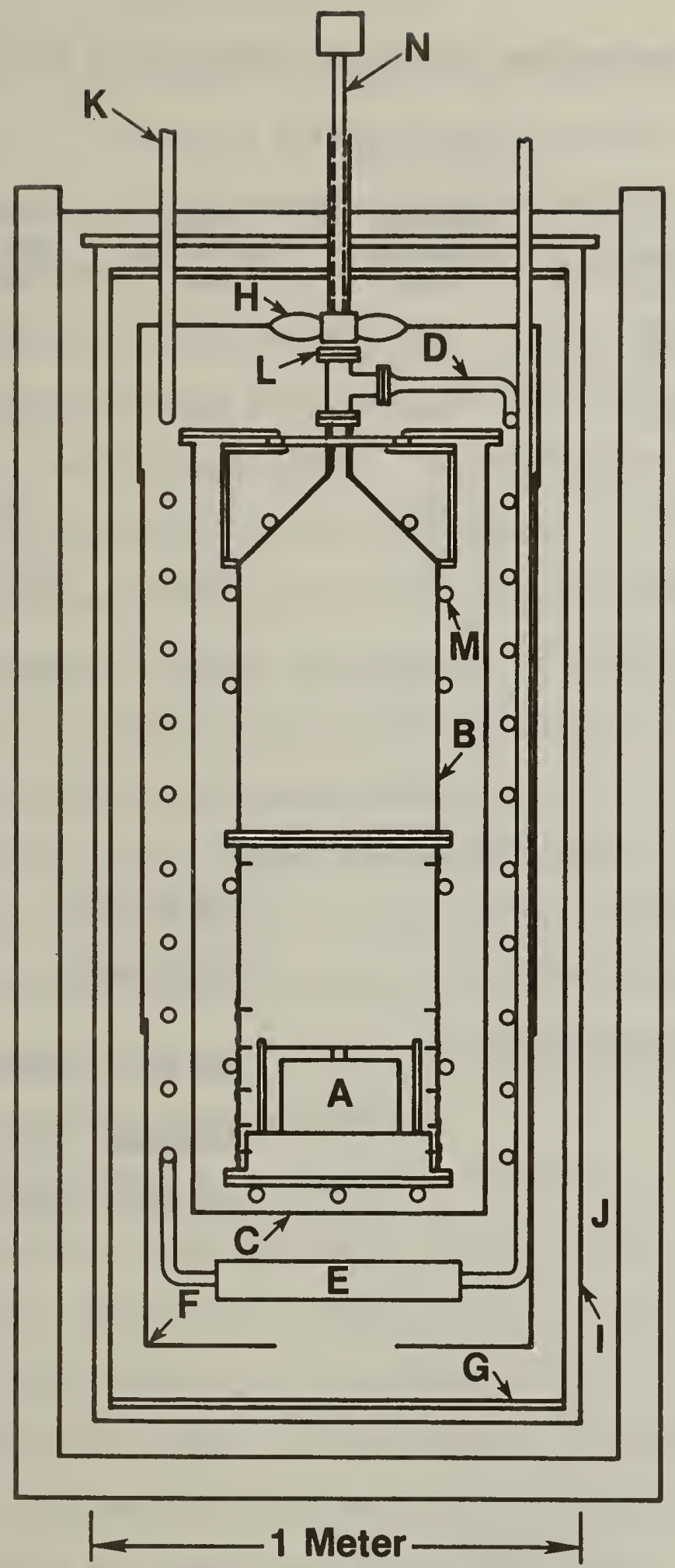

Figure 1. Diagram of the $2.5 \mathrm{~kg}$ capacity flow calorimeter. A denotes the sample pellet, $B$ the combustor, $C$ the combustor enclosure, $D$ the exhaust coil, $E$ the collector, $F$ the flow shield, $G$ the calorimeter vessel, $H$ the stirrer, I the submarine jacket, $J$ the jacket water, $K$ a quartz thermometer, $\mathrm{L}$ the window, $\mathrm{M}$ the quick-cool heat exchange system, and $\mathrm{N}$ the boroscope. 
Table 1. Speciflcations for the $2.5 \mathrm{~kg}$ capacity flow calorimeter.

\begin{tabular}{lcccc} 
& \multicolumn{5}{c}{$\begin{array}{c}\text { Dimensions } \\
\text { Outside } \\
\text { Component }\end{array}$} & $\begin{array}{c}\text { Helght } \\
(\mathrm{cm})\end{array}$ & $\begin{array}{c}\text { Wall } \\
\text { Diameter } \\
(\mathrm{cm})\end{array}$ & $\begin{array}{c}\text { Thickness } \\
(\mathrm{mm})\end{array}$ & $\begin{array}{c}\text { Total } \\
\text { Mass } \\
(\mathrm{kg})\end{array}$ \\
$\begin{array}{l}\text { Combustor } \\
\text { Combustor }\end{array}$ & 155 & 41 & 3.2 & 74 \\
$\begin{array}{l}\text { Enclosure } \\
\text { Flow Shield }\end{array}$ & 213 & 61 & 4.8 & 196 \\
$\begin{array}{l}\text { Calorimeter } \\
\text { Vessel }\end{array}$ & 236 & 79 & 1.6 & 73 \\
$\begin{array}{l}\text { Submarine } \\
\text { Vessel }\end{array}$ & 243 & 91 & 4.8 & 390 \\
\end{tabular}

Additional Specifications

Calorimeter water

Jacket water

Heat capacity of calorimeter
98011 ters

216011 ters

$0.4 \mathrm{MJ} / \mathrm{K}$ (assembly)

$4.1 \mathrm{MJ} / \mathrm{K}$ (water)

$4.5 \mathrm{MJ} / \mathrm{K}$ (total) 
welded to the outside of the combustor wall.

The combustor is surrounded by a concentric cylindrical vessel, the combustor enclosure, C. The space between B and C contains tubes that supply oxygen to the combustor, thermocouples mounted on the combustor wall, tubes (M) of a quick-cool heat exchange system (also welded to the outside of the combustor), and argon gas to reduce corrosion of these components.

The product gas leaves the top of the combustor and then passes downward through a ten-turn heat-exchange coll, D, then through the collector, E, and finally through the exit tube out of the calorimeter. The heat exchange coil transfers heat from the product gas to the calorimeter water. Most of the water formed in the combustion reaction condenses and is trapped in the collector. The calorimeter water is directed past the heat exchange colls by means of a flow shield, F. Water is drawn through the bottom port (20 $\mathrm{cm}$ diameter) in the flow shield, past the colls, and is mixed by stirrer blades, $H$, mounted in the top port of the shield. Water returns to the bottom port via the annular space between the calorimeter vessel, G, and flow shield at a nominal water flow rate of 380 liters per minute (lpm). Thus, the calorimeter water makes a complete circuit of the flow path every 2.5 minutes.

The calorimeter vessel is surrounded by a concentric cylindrical vessel, the submarine vessel I, which constitutes the innermost portion of the constant temperature jacket. The $2.5 \mathrm{~cm}$ air space between the vessels reduces the heat exchange between the jacket and the calorimeter proper. The submarine vessel is submerged in the stirred water, $J$, of the jacket. The calorimeter water temperature is monitored by a quartz oscillator thermometer, K. A similar thermometer monitors the temperature of the jacket water. Temperatures of the inlet oxygen supply and the product gas are monitored with thermocouple probes whose junctions are located in the gas tubes at the level of the calorimeter 
vessel $11 d$.

The combustion reaction is monitored visually through the window, L, sealed to the Inline port of a tee in the product gas line (at the top of the combustor in Figure 1) by means of the boroscope, N, which extends through the hollow stirrer shaft. The boroscope is attached to a TV camera which is connected to a video monitor-recording system.

From the calorimeter vessel, the product gas passes through a mixing chamber and flowmeter. Just beyond the flowmeter, a portion of the gas is continuously withdrawn for analysis. Part of this gas is dried and passed through dedicated infrared detectors for $\mathrm{CO}$ and $\mathrm{CO}_{2} \cdot \mathrm{A}$ second part is passed through a scanning infrared detector used to monitor various trace components (hydrocarbons, $\mathrm{SO}_{2}, \mathrm{HCl}$, etc.). The remaining part of this gas is passed through a cooled-mirror type of automatic dew point detector to monitor water vapor. These detectors in combination with three manometers and six thermocouples (to monitor gas temperatures) are used to determine the composition of the product gas.

A dual minicomputer based data logging and computation system is used to monitor the outputs of a total of 33 thermocouples, two quartz thermometers, eight flowmeters, and seven instruments in the product gas analysis train.

\subsection{Description of a Typical Experiment}

Before ignition of the sample, the calorimeter water temperature is monitored for one hour after the drift rate becomes constant. During this initial drift period and in a similar length final drift period after the combustion reaction, the calorimeter water is pumped through the quick-cool heat exchange tubes ( $M$ of Figure 1) in the combustor wall by a gear pump mounted in the calorimeter water. This increases the rate of temperature equilibration of the combustor with the calorimeter water and insures that the calorimeter proper 
is more nearly isothermal during the drift periods.

Ten minutes prior to ignition, the supply of water to the quick-cool heat exchange system is turned off (i.e. water from the gear pump is returned directly to the calorimeter vessel) and the water remaining in the quick-cool system is blown out with air. The combustor is flushed with oxygen. During the combustion, oxygen is supplied from a manifold containing eight 6200 liter (STP) standard oxygen tanks and six mass flow controllers. Oxygen is supplied to the combustor, the underside of the viewing window (to prevent water condensation), and the product gas as it leaves the collector. The last supply reduces the dew point of the product gas below room temperature in order to prevent water from condensing in the analysis train. Typical flow rates are $1501 \mathrm{pm}$ to the combustor, $101 \mathrm{pm}$ to the viewing window, and $1101 \mathrm{pm}$ to dilute the product gas for a total flow of $2701 \mathrm{pm}$.

Sample burning times were approximately 32 minutes for RDF-2 and microcrystalline cellulose, and about 42 minutes for $\mathrm{RDF}-4$. The $\mathrm{CO}_{2}, \mathrm{H}_{2} \mathrm{O}$, and $\mathrm{CO}$ concentrations in the product gas during the combustion of an RDF- 4 pellet are shown in Figure 2. The peak and average $\mathrm{CO}_{2}$ concentrations over the first ten minutes of the combustion are 52 and 38 mole percent, respectively. The latter concentration corresponds to an oxygen supply rate of about 2.5 times stoichiometry. The $\mathrm{H}_{2} \mathrm{O}$ concentration reaches a maximum of 2.4 mole percent (i.e. dew point of $16^{\circ} \mathrm{C}$ ) at 30 minutes; the abrupt fall in concentration at 42 minutes indicates that the combustor has been completely flushed of product gas. The occurrence of two peaks in the $C O$ concentration versus time is typical of all the RDF samples. In Figure 2, the initial and final maximum $C 0$ concentrations are 0.016 and 0.027 mole percent, respectively. The initial peak always occurs near the time of the maximum rate of production of $\mathrm{CO}_{2}$; the final peak occurs near the end of the visual burning when the ash tends to inhibit the combustion. 
CONCENTRATION / PPM

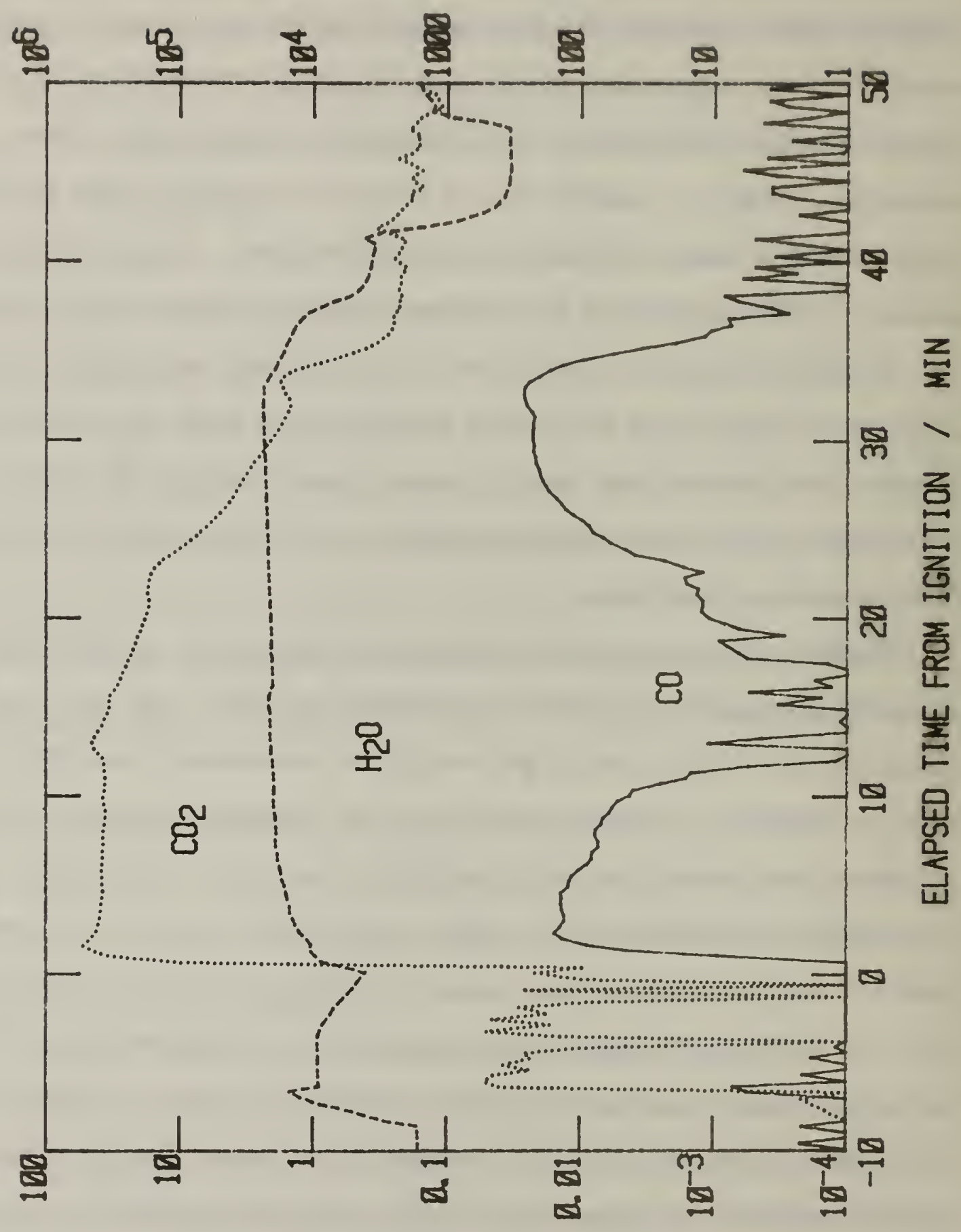

zTOW / NOILYYINJJNOJ

Figure 2. A plot of the concentrations of gaseous carbon dioxide, water, and carbon monoxide as a function of time for a typical experiment on RDF. 
The average Co concentration in a cellulose combustion is about a factor of fifty smaller than that shown in Figure 2.

The temperature of the produot gas as it leaves the top of the combustor rises to about $400{ }^{\circ} \mathrm{C}$ in the first minute of the oombustion, gradually increases to a maximum of about $450^{\circ} \mathrm{C}$ between 12 and 15 minutes after 1gnition, and then decays exponentlally thereafter. The temperatures of the combustor wall and of the oxygen gas as it leaves the preheat oolls inorease more gradually to peak values at about the same time and deoay similarly. The peak values of the temperatures of the wall and adjacent preheat colls within $25 \mathrm{~cm}$ of the ash pan are between 600 and $700{ }^{\circ} \mathrm{C}$.

When the temperature of the combustor base plate has deoreased to $220{ }^{\circ} \mathrm{C}$, the calorimeter water is again oirculated through the quick-cool heat exchange system. This safely removes the appreolable excess heat stored in the combustor. A plot of the calorimeter water temperature vs elapsed time for the experiment corresponding to Figure 2 is shown by the solid Iine of Figure 3. The temperature of the calorimeter water had increased $8{ }^{\circ} \mathrm{C}$ after an elapsed time of 60 minutes when the quick-cool system was activated. During the next 10 minutes, when most of the excess heat was removed, the temperature of the calorimeter water increased by $1.2{ }^{\circ} \mathrm{C}$. This increase corresponded to $13 \%$ of the total heat liberated by the combustion reaction.

After the drift rate of the calorimeter water attains a steady value, temperature readings are made for an additional hour which corresponds to the final drift period. The data points in Figure 3 are the deviations of the calorimeter water temperature from the drift period equation. (The ordinate scale is -30 to $+30 \mathrm{mK}$.) The set of data points on the right of the figure indicates that the final drift period begins about 150 to 180 minutes after ignition. A correction is made for the heat exchange between the calorimeter 
TOBS. - TCALC. / MILLIKELVIN

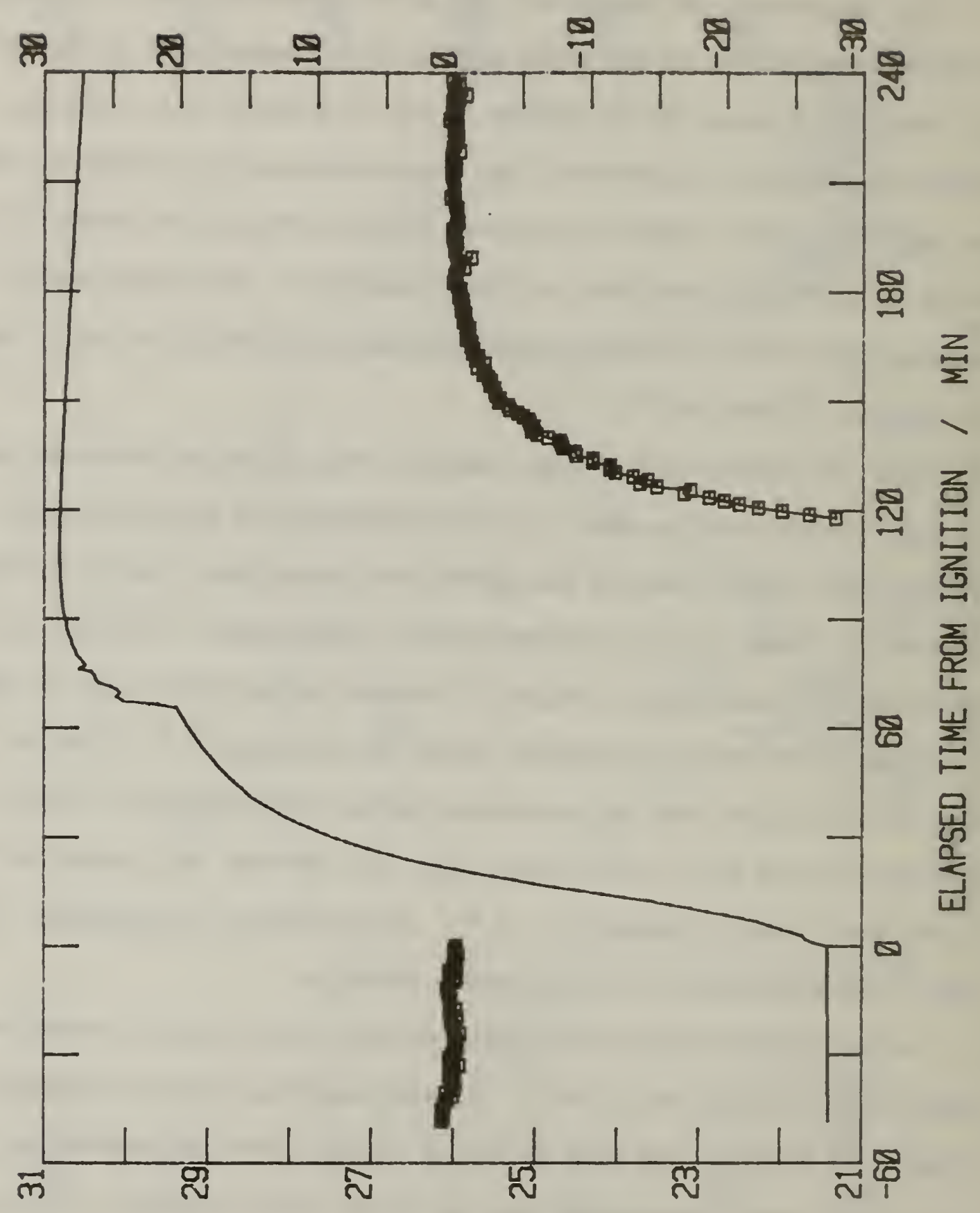

ว ง

Figure 3. A plot of the temperature rise of the calorimeter water plus the deviation of the observed data points from the smooth curve fit to the data during the drift periods. 
proper and the jacket during the three hour time interval between the two drift periods. This correction amounts to about $4 \%$ of the observed calorimeter water temperature rise which was between 6.0 and $9.5{ }^{\circ} \mathrm{C}$ for all experiments.

\section{Sample Preparation and Measurement Protocol}

To resolve the dispute about the validity of the current method of determining the caloriflc value of MSW, two problems were addressed. The first is the sampling problem: How does one obtain a representative gram-size sample from a kilogram-size quantity of RDF-4? The second is the processing problem: Does processing MSW down to $2 \mathrm{~mm}$ particle size (RDF-4) alter its calorific value significantly (i.e. one percent or more)?

Both the sampling and processing problems were examined in context of the variability of MSW for two weeks, a time period appropriate to a specification test of an incinerator-boiler system. Thirteen to twenty-three kilograms of RDF-2 were obtained on each of ten consecutive working days (5 days per week for a 2 week period from January 10 to 21, 1983) from the Baltimore County Resource and Recovery Facility in Cockeysville, Maryland. Each sample was removed from the conveyor belt immediately beyond the primary shredder before any further processing occurred. The material was brought to NBS each day, dried for 12 hours at $105{ }^{\circ} \mathrm{C}$ to determine its initial molsture content, and then stored at $5{ }^{\circ} \mathrm{C}$.

Ideally, the processing problem could be solved by comparing the calorific value of identical pairs of kilogram-size samples of dried RDF-2, one unprocessed and the other processed. We attempted to prepare such identical kilogram-size samples by sorting each day's material into eight categories and then reconstituting the material into $2.5 \mathrm{~kg}$ samples having the same relative mass composition as the whole.

A summary of the results of hand sorting plus the initial moisture content 
are given in Table 2. The material was hand sorted into metal, combustible, and noncombust1ble fractions. Metals were separated 1nto magnet10 and nonmagnet10 components. The combustible fraction was separated into wood/vegetable matter, text1les, plastios, and paper. The noncombustible fraction was divided into glass/ceramics and "fines" (primarily grit and sand). The compositions according to main groups are given in lines 10 through 12 of Table 2. Metals were omitted from the reconstituted material. The combustible and noncombustible compositions of the samples actually burned in the flow and bomb calorimeters are listed in the last two rows of Table 2. The sorting and reconstituting of the material for each day required the efforts of three or more people for approximately one day.

Four of the ten day's material were selected for our study: days 6 and 9, which had the largest and smallest noncombustible content, respectively, and days 4 and 7 , which had intermediate noncombustible contents. The bottom row of each of these days is underlined in Table 2.

Processed MSW consists of a low density component, fluff, which resembles chopped up cotton fibers, and a high density component which resembles sand or metal particles. Some high density material is entrained in the fluff; this entrainment is not uniform. Sampling problems arise because of segregation of the high and low density components. The sampling technique used in the first NBS study [3] of the variability of MSW for a two week period in January 1980 consisted of blending (in drums filled with steel balls), coning and quartering, and taking gram-size grab samples. This method was found to be unsatisfactory. In that study, the percent coeffiolent of varlation ${ }^{(+)}, \$ C V$, of the enthalpy of

(+) $100 \times(s /$ average ), wheres is the standard deviation of a single measurement. 
Table 2. Composition of municipal solid waste obtained Jan 10-21, 1983, from the Baltimore County Resource and Recovery Facility.

\begin{tabular}{llllllllllll}
\multicolumn{10}{c}{ Mass Percent (Dry) } \\
Day & 1 & 2 & 3 & 4 & 5 & 6 & 7 & 8 & 9 & 10
\end{tabular}

1) Initial Moisture $\quad \begin{array}{llllllllll}35.0 & 28.9 & 52.7 & 27.6 & 29.3 & 34.3 & 25.1 & 30.8 & 22.0 & 26.4\end{array}$

2) Metal (Magnetic) $\quad \begin{array}{llllllllll}9.1 & 8.6 & 6.4 & 5.0 & 5.7 & 6.0 & 2.6 & 0.3 & 2.2 & 3.9\end{array}$

3) Metal (Nonmagnetic) $\quad \begin{array}{llllllllll}1.6 & 1.3 & 1.4 & 1.3 & 1.9 & 1.5 & 1.3 & 0.9 & 0.6 & 1.5\end{array}$

4) Wood, Vegetable $\quad \begin{array}{lllllllllll}1.4 & 0.5 & 0.7 & 0.8 & 2.2 & 1.3 & 0.4 & 0.2 & 2.5 & 1.5\end{array}$

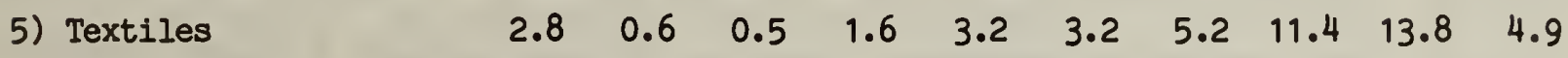

$\begin{array}{lllllllllll}\text { 6) Plastics } & 5.3 & 4.6 & 4.6 & 3.3 & 5.4 & 6.2 & 8.2 & 12.8 & 6.6 & 6.2\end{array}$

$\begin{array}{lllllllllll}\text { 7) Paper } & 58.2 & 63.0 & 62.2 & 66.2 & 57.9 & 55.8 & 67.7 & 58.6 & 64.3 & 69.8\end{array}$

8) Glass, Ceramics $\quad \begin{array}{llllllllll}1.0 & 3.4 & 2.6 & 2.6 & 3.5 & 2.4 & 0.8 & 0.5 & 0.3 & 0.9\end{array}$

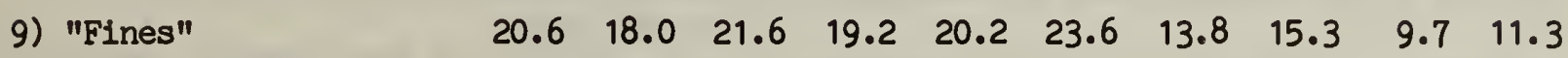

$\begin{array}{lllllllllll}\text { 10) Metals } & 10.7 & 9.9 & 7.8 & 6.3 & 7.6 & 7.5 & 3.9 & 1.2 & 2.8 & 5.4\end{array}$

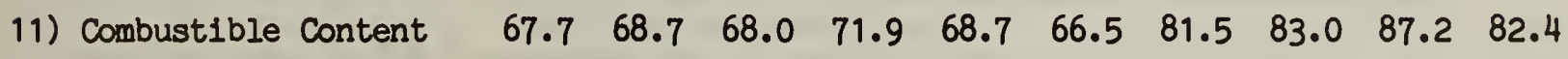

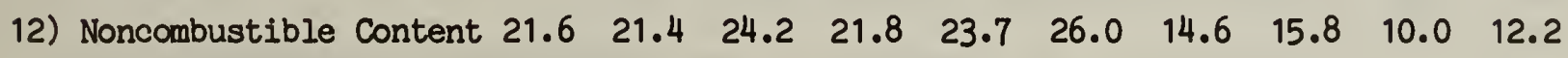

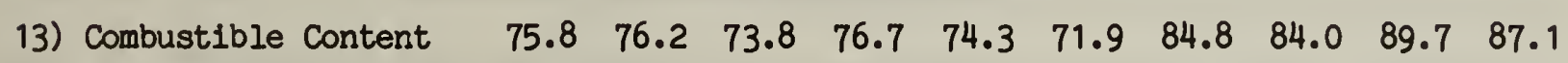

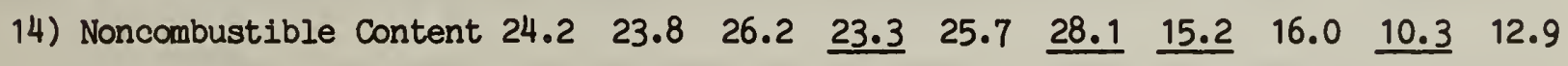


combustion on a dry basis was 3.28 for supposed identical gram-size samples of RDF- 4 burned in a bomb calorimeter. The corresponding quantity for a pure (or truly homogeneous) material should be of the order of $0.1 \%$.

For this study, we introduced a new technique for obtaining gram-size test samples. A Brinkmann Co. Sample Divider PTZ ${ }^{(+)}$was used. It consists of a central cup from whose bottom surface tubes extend outward and downward to collector bottles. In the model we used there are elght tubes and elght bottles. The cup, tubes, and bottles rotate around the central vertical axis of the cup. The sample is introduced into the divider through a funnel feeding a horizontal vibrating trough which teases the sample into the divider cup.

An initial assessment of the new sample division technique showed this method to be superior to the coning and quartering procedure used in the variability study [3]. This conclusion is confirmed by the results cited in section 4 .

The measurement protocol adopted for our study is summarized in Table 3. Four bags of the reconstituted kilogram-size samples of RDF-2 were selected from each of the four days. The contents of two of the bags, designated $A$ and $B$, were burned in the large flow calorimeter (Step 2C, Table 3) without further processing after drying to determine the residual moisture (Step 2A). A known amount of water was added to each of the samples and then each sample was compacted to form a pellet (Step 2B). The water was added to improve the cohesion of the pellet.

\footnotetext{
(+) The commercial sources cited in this paper are included to adequately describe the experimental procedures. Such identification does not imply recommendation or endorsement by the National Bureau of Standards.
} 
Table 3. Measurement protocol.

1. Select four $2.5 \mathrm{~kg}$ samples from each day. For example:

Day 4, label samples A4, B4, C4, D4.

2. $\mathrm{A} 4, \mathrm{~B} 4$ A) Dry.

B) Add water and pelletize.

C) Burn in flow calorimeter.

3. C4, D4: A) Reduce to $2 \mathrm{~mm}$ particle size.

B) Blend, take grab sample (40 grams).

C) Divide to obtain test samples (2 grams each).

D) Recombine remainder of $\mathrm{C} 4$ and $\mathrm{D} 4$ to obtain two identical kilogram-size samples. Label E4, E'4.

E) Test samples: two sets of two combustion bomb calorimeter, two residual moisture, and two furnace ash determinations (one set for each bag).

4. E4, E'4: A) Pelletize.

B) Burn in flow calorimeter. 
The contents of the remaining two bags, designated $C$ and $D$, were processed to $6 \mathrm{~mm}$ sieve size using a Williams Hammer Mill and then to $2 \mathrm{~mm}$ sieve size using a Wiley Mill (Step 3A). A diagram of the measurement protocol for bags C and $D$ is given in Figure 4. Powdered dry ice was mixed with the material in the throat of the Wiley Mill to prevent excessive local heating. The resulting RDF-4 of each bag was then blended in a vee blender and a forty-gram grab sample was removed (Step 3B). (The grab sample was saved for future use in another study.) Gram-size test samples were then obtained from the milled, blended material of bag $C$ and bag $D$ using the Brinkmann Sample Divider (Step 3C). In Step 3D, the remainder of each bag was divided into two equal parts. One part of bag $C$ and one part of bag $D$ were combined to form the sample of bag $E$ and similarly for identical bag $E^{\prime}$. Kilogram-size pellets of RDF-2 (Step 2B) and RDF-4 (Step 4A) were prepared by placing the sample in a die piece and compressing it with a total force of $534 \mathrm{kN}$.

Masses of samples were recorded before, after, and during each step of the measurement protocol to account for sample loss. Individual measurements in sets made with either the bomb or flow calorimeter were carried out in a random order.

In subsequent sections of this paper, the labels $C$ and $D$ refer to the gramsize test samples withdrawn from bags $C$ and $D$, respectively, before step $3 D$ in which the remainder of bags $C$ and $D$ were split and recombined to obtain bags $E$ and $E^{\prime}$. The strategy behind step $3 D$ was to take further advantage of the improved capability of the Brinkmann Sample Divider to divide the sample into identical parts. Having prepared identical gram-size samples in Step 3C, we prepared identical kilogram-size samples in Step 3D. Hence, differences in the enthalpy of combustion of each pair of $E$ and $E^{\prime}$ samples for a given day afford a direct measure of the measurement precision of the new calorimeter on an actual 


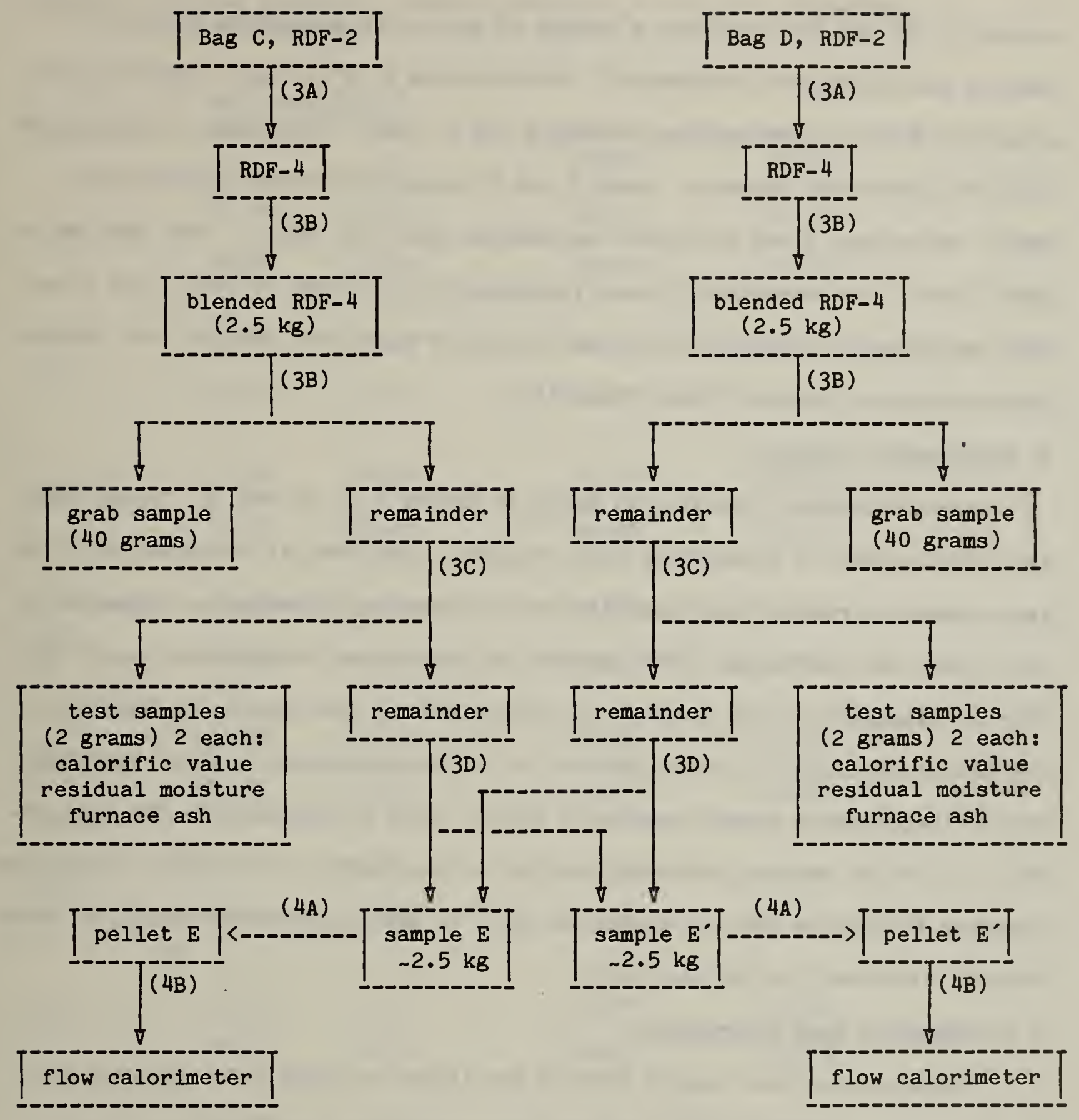

Figure 4. Diagram of the sample division technique used to prepare gramsize test samples ( $C$ and $D$ ) for the bomb calorimeter studies and kilogram-size samples ( $E$ and $E^{\prime}$ ) for the flow calorimeter studies from $2.5 \mathrm{kilogram}$ hand sorted and reconstituted samples in bags $C$ and $D$. The steps given in Table 3 are indicated in the parentheses along the arrows. 
sample of RDF (as distinct from a sample of pure cellulose which does not contain noncombustible components). While labels E, $E^{\prime}, A$ and $B$ refer to kilogram-size samples, the samples of bags $E$ and $E^{\prime}$ differ from those of bags $A$ and $B$ in two important respects. Bags $E$ and $E^{\prime}$ contain processed material (i.e. RDF-4) while bags $A$ and $B$ contain unprocessed MSW (i.e. RDF-2). The samples in bags $E$ and $E^{\prime}$ are essentially exact replicates while those in bags $A$ and $B$ are only approximately identical (i.e. to the extent that hand sorting into general classifications given in Table 2 permits).

\section{Experimental Results}

The experimental results are given in Tables 4, 6, 7, and 9. Three important conclusions are drawn from these results. The first is concerned with the improvement in results obtained with the new sampling technique as compared to the coning and quartering technique used in the earlier variability study [3]. This is discussed in the analysis of the gram-size test results in section 4.1. The second conclusion concerns whether or not gram-size test samples represent their kilogram-size parent samples of RFD-4. This is discussed in the comparison of flow and bomb calorimetry results in Section 4.2.1. The final conclusion concerns whether or not processing of RDF-2 to RDF-4 alters the calorific value. This is discussed in Section 4.2.2.

\section{1 Combustion Bomb Calorimetry}

The gram-size test sample results are listed in Table 4 for sampling days 4, 6, 7, and 9. They consist of duplicate results for each sample of the enthalpy of combustion (ASTM Method E711-81), bomb ash (dried residue from a combustion bomb experiment) and furnace ash (ASTM Method E830-81). All results were converted to a dry basis using moisture contents obtained with ASTM Method E790-81. In the furnace ash test, the sample is combusted in air in a furnace at $575{ }^{\circ} \mathrm{C}$ for two hours. 
Table 4. Ash and combustion bomb calorimetry results for two-gram test samples.

\begin{tabular}{|c|c|c|c|c|}
\hline Sample & $\begin{array}{c}\text { Ash (Dr } \\
\text { Furnace } \\
\varnothing\end{array}$ & $\begin{array}{c}\text { Basis) } \\
\text { Bomb } \\
q\end{array}$ & $\begin{array}{l}\mathrm{HHV} 2 \\
\mathrm{MJ} / \mathrm{kg}\end{array}$ & $\begin{array}{r}\mathrm{HHV} 3-\mathrm{B} \\
\mathrm{MJ} / \mathrm{kg}\end{array}$ \\
\hline \multirow{2}{*}{ C4 } & 34.45 & 33.62 & 14.619 & 22.022 \\
\hline & 34.54 & 33.50 & 14.555 & 21.886 \\
\hline \multirow{2}{*}{ D4 } & 32.73 & 31.54 & 14.867 & 21.716 \\
\hline & 32.30 & 31.21 & 14.857 & 21.598 \\
\hline \multirow{2}{*}{ c6 } & 37.82 & 34.58 & 14.678 & 22.436 \\
\hline & 37.19 & 35.67 & 14.546 & 22.612 \\
\hline \multirow{2}{*}{ D6 } & 37.67 & 36.18 & 14.509 & 22.735 \\
\hline & 36.89 & 35.51 & 14.714 & 22.817 \\
\hline \multirow{2}{*}{ C7 } & 27.76 & 26.78 & 16.273 & 22.224 \\
\hline & 28.30 & 26.58 & 16.506 & 22.480 \\
\hline \multirow{2}{*}{ D7 } & 25.04 & 24.19 & 17.254 & 22.760 \\
\hline & 25.49 & 23.13 & 17.253 & 22.443 \\
\hline \multirow{2}{*}{ c9 } & 17.89 & 16.41 & 18.200 & 21.772 \\
\hline & 17.68 & 16.31 & 18.221 & 21.773 \\
\hline \multirow{2}{*}{ D9 } & 17.43 & 15.84 & 18.336 & 21.787 \\
\hline & 17.55 & 16.57 & 18.325 & 21.966 \\
\hline
\end{tabular}


Table 5 summarizes the statistical analysis of the results; the methods are summarized in references [5] and [6]. The percent coefficient of variation, \%cv, for the between-day, within-day, and within-bag variability are calculated for furnace ash, bomb ash and calorific values. HHV2 and HHV3 are the negative of the enthalpy of combustion on a moisture free and a moisture-ash free basis, respectively. HHV3-B refers to the use of the bomb ash value in the calculations; HHV3-F refers to the use of the furnace ash value in the calculations. For sake of comparison, the corresponding results for the 1980 variability study are given in the lower half of Table 5. The total $\% \mathrm{CV}$ in column 6 is the square root of the sum in quadrature of the $\mathrm{CCV}^{\prime} \mathrm{s}$ given in the preceding three columns. In this work, the within-bag \%cV, which corresponds to the combined measurement and sampling error for gram-size samples, is substantially less for all properties than in the prior variability study [3]. The small value for the HHV2 within-bag $\% \mathrm{CV}$ and its close agreement with the within-bag values for HHV3-B and HHV3-F indicates that the new sample division procedure has reduced our sampling error for gram-size samples to less than $0.8 \%$. The within-day $\% \mathrm{CV}$ for HHV2, 2.0\%, suggests that the extra error introduced in failing to prepare equivalent kilogram-size samples (C and D) for each day by hand sorting and recombination is somewhat larger in size than the combined measurement and sampling error. (The label "within-day \%CV" is the between-bags \%CV estimated within days.)

The fact that the within-day and within-bag \%CV for HHV3-B are about the same while the corresponding values for HHV2 are not indicates that the hand sorting and reconstituting procedure failed to yield equivalent samples for each day primarily because the initial noncombustible contents were different. The lower between-day $\$ \mathrm{CV}$ for HHV3-B (or HHV3-F) as contrasted to that for HHV2 suggests that the primary variability in the MSW stream is in its ash (and 
Table 5. Summary of statistical analysis of ash and combustion bomb calorimetry results for two-gram test samples.

\section{Components of Variability, \%CV}

Property

(Dry basis)

Furnace Ash, \%

Bomb Ash, \%

$\mathrm{HHV} 2, \mathrm{MJ} / \mathrm{kg}$

HHV $3-B, M J / k g$

HHV $3-\mathrm{F}, \mathrm{MJ} / \mathrm{kg}$
Average

Within

Bag
Within Between

Day Days Total

( 4 days, this work)

28.8

1.2

4.1

29.9

30.2

27.4

1.7

4.8

31.1

31.5

16.108

0.5

2.0

10.9

11.1

22.189

0.6

0.6

1.9

2.1

22.649

0.8

0.3

2.5

2.6
January 1980 Study (10 days, [3])

$\begin{array}{llrrrr}\text { Furnace Ash, \% } & 31.8 & 6.5 & 23.0 & 29.8 & 38.2 \\ \text { Bomb Ash, \% } & 28.9 & 10.6 & 15.6 & 33.7 & 38.6 \\ \text { HHV2, MJ/kg } & 15.393 & 3.2 & 6.6 & 11.2 & 13.4 \\ \text { HHV3-B, MJ/kg } & 21.664 & 1.6 & 1.5 & 3.7 & 4.3 \\ \text { HHV3-F, MJ/kg } & 22.523 & 5.1 & 5.4 & 3.1 & 8.0\end{array}$


initial moisture) content and not the calorific value of its combustible content. The latter was also a conclusion of the first variability study [3]. The larger average value for HHV3-F as compared to HHV3-B is a reflection of the fact that the percentage of furnace ash is greater than the percentage of bomb ash. The data of Table 4 can be used to calculate a value of furnace ash minus bomb ash of $1.44 \pm 0.33 \%$. The uncertainty, $.33 \%$, is the imprecision of the mean at the $95 \%$ confidence level ${ }^{(+)}$.

It should be noted that the total $\mathrm{KCV}$ reflects primarily the day-to-day variability and not the variability of the measurement processes being studied here. The latter is characterized by the within-bag and, to a certain extent, the within-day \%CV. The fact that the between-day $\% \mathrm{CV}$ is much larger than the within-bag or within-day \%CV's in Table 5 does not mean that the between-day $\% \mathrm{CV}$ is the limit to which a two-week supply of MSW (i.e. an incinerator test sample) can be characterized. Rather it means that each day's properties must be characterized separately and/or samples should be composited as described by Mandel and Paule [5].

It should also be noted that neither the within-day or between-day \%CV of this work are strictly comparable to the corresponding parameters of the earlier variability study [3]. The values of the within-day $\mathrm{KCV}$ of this work have been deliberately altered by the hand sort and reconstitution procedure. The between-day \%CV is for only four of ten days samples of MSW and the four days were not selected at random.

(+) For this and all other statements labeled "imprecision", we are using the product of the standard deviation of the mean and the appropriate Student $t$ factor at the $95 \%$ confidence level. 


\subsection{Combustion Flow Calorimetry}

Six determinations of the energy equivalent (i.e. apparent heat capacity) of the flow calorimeter gave a \% CV for a single measurement of $0.26 \%$. The average energy equivalent was $4.509 \mathrm{MJ} / \mathrm{K}$ with an imprecision of $\pm 0.012 \mathrm{MJ}$ which is $0.27 \%(0.26 \% \times$ Student $t / \sqrt{\mathrm{n}})$ of the mean.

In the calculation of the flow calorimetry results, we have omitted several minor calormetric corrections (e.g. for small amounts of $\mathrm{CO}$ in the product gas, for small amounts of unburned sample in the ash, etc.). We do not expect the absence of these corrections to affect our results or conclusions in a practically significant manner. For convenience the results of the flow calorimetry will, henceforth, be referred to as flow results. 4.2.1 Flow Calorimetry of RDF-4.

The flow and bomb results on processed MSW (RDF-4) are summarized in Table 6. The columns labeled furnace ash, bomb ash, bomb HHV2, bomb HHV3 are calculated from the averages of the gram-size test measurements on C and D weighted by the amounts of sample from bags $C$ and $D$ which form the samples in bags $E$ and $E^{\prime}$. (See Table $7^{\prime}$ )

The analysis of the data in Table 6 is given in Table 8 . The first four rows show the average and imprecision of the paired differences for values of flow ash minus furnace ash and flow minus bomb values for ash, HHV2 and HHV3. The day average rather than each of the paired differences of flow minus bomb values for ash, HHV2, and HHV3 were used to evaluate imprecisions as the differences tend to group themselves into within-day sets.

The first two rows of Table 8 show that the average flow ash is $2.7 \pm 1.5 \%$ greater than the average bomb ash and is $2.5 \pm 1.9 \%$ smaller than the average furnace ash. These differences are consistent with the relation between the combustion zone temperatures (i.e. bomb > flow > furnace). They are also 
Table 6. Flow and bomb calorimetry results on processed MSW (RDF-4).

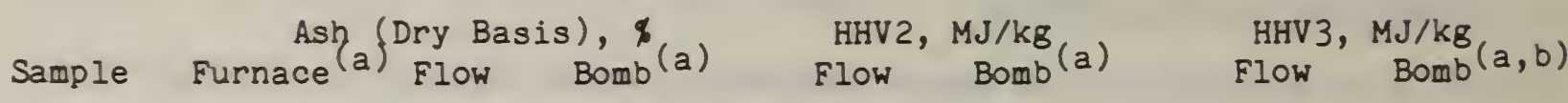

$\begin{array}{llllllll}\text { E4 } & 33.51 & 32.78 & 32.48 & 14.732 & 14.723 & 21.918 & 21.804 \\ \text { E'4 } & 33.50 & 32.94 & 32.47 & 14.838 & 14.725 & 22.126 & 21.804 \\ \text { E6 } & 37.43 & 36.17 & 35.49 & 14.458 & 14.612 & 22.650 & 22.650 \\ \text { E'6 } & 37.43 & 36.32 & 35.49 & 14.489 & 14.612 & 22.752 & 22.650 \\ \text { E7 } & 26.63 & 26.23 & 25.17 & 16.725 & 16.821 & 22.671 & 22.479 \\ \text { E'7 } & 26.62 & 26.11 & 25.17 & 16.735 & 16.821 & 22.648 & 22.479 \\ & & & & & & & \\ \text { E9 } & 17.63 & 17.20 & 16.28 & 18.425 & 18.272 & 22.253 & 21.826 \\ \text { E'9 } & 17.64 & 17.11 & 16.28 & 18.295 & 18.271 & 22.070 & 21.825\end{array}$

(a) Calculated from averages of bomb calorimetry measurements on bags $C$ and $D$ and known mass fractions of $C$ and $D$ used to make up bags $E$ and $E^{\prime}$.

(b) HHV 3-B 
Table 7. Mass Fractions of Bags $E$ and $E^{\prime}$ contributed by Bags $C$ and $D$. Components (Dry Basis)

$\begin{array}{lllll}\text { Bag } & \text { Bag } & \text { Mass Fraction } & \text { Bag } & \text { Mass Fraction } \\ \text { E4 } & \text { C4 } & 0.50333^{(a)} & \text { D4 } & 0.49667 \\ E^{\prime} 4 & \text { C4 } & 0.49891 & \text { D4 } & 0.50109 \\ \text { E6 } & \text { C6 } & 0.49901 & \text { D6 } & 0.50099 \\ \text { E}^{\prime} 6 & \text { C6 } & 0.49862 & \text { D6 } & 0.50138 \\ \text { E7 } & \text { C7 } & 0.50078 & \text { D7 } & 0.49922 \\ E^{\prime} 7 & \text { C7 } & 0.50036 & \text { D7 } & 0.49964 \\ \text { E9 }^{\prime} & \text { C9 } & 0.49043 & \text { D9 } & 0.50957 \\ E^{\prime} 9 & \text { C9 } & 0.49478 & \text { D9 } & 0.50522\end{array}$

(a) Fifth significant figure is carried for computational purposes. 
Table 8. Analysis of flow and bomb calorimetry results on processed MSW $(\mathrm{RDF}-4)$.

Property Difference

(Dry Basis)

1) Flow Ash-Bomb Ash, \%

2) Flow Ash-Furnace Ash, \%

3) HHV2 Flow-HHV2 Bomb, MJ/kg

4) HHV 3 FlOW-HHV $3(\mathrm{c})$ Bomb, $\mathrm{MJ} / \mathrm{kg}$

$\begin{array}{cl}\text { Average } & \text { Imprecision }(a) \\ +0.76(+2.7 \%)(b) & 0.41(1.5 \%) \\ -0.69(-2.5 \%) & 0.54(1.9 \%) \\ -0.020(-0.1 \%) & 0.178(1.1 \%) \\ +0.197(+0.9 \%) & 0.187(0.8 \%)\end{array}$

Components of Variability, \%cV
Average

9) Ash, Furnace, \%

10) $\mathrm{HHV} 2, \mathrm{Bomb}, \mathrm{MJ} / \mathrm{kg}$

11) HHV 3, Bomb, $\mathrm{MJ} / \mathrm{kg}$

(a) product of Student $t$ for the $95 \%$ confidence level and the standard deviation of the average.

(b) percent of flow value

(c) HHV 3-B
28.11

16.087

22.386

27.35
Measurement

Error

0.3

0.4

0.5

1.5

Day

30.0

11.3
Between

28.80

16.107

22.189 
consistent with the observed variation in the amount of furnace ash formed as a function of furnace temperature [7]. The average difference of the flow minus bomb values for HHV2 is $-0.1 \%$ of the average HHV2 flow value. This difference is not statistically different from zero as the $95 \%$ confidence interval is from -1.2 to +1.0\%. The average difference of the flow minus bomb values for HHV 3 is $+0.9 \%$ of the average HHV3 flow value. The difference is statistically different from zero as the $95 \%$ confidence interval is from +0.1 to $+1.7 \%$. However, the interval misses zero by such a small amount that we do not regard the nonoverlap to be practically important.

The average difference of the flow minus bomb values for HHV 3 can be different from zero even if the HHV2 difference were zero, because, in this work the average difference of the flow minus bomb ash values is $+0.8 \%$ which is $2.7 \%$ of the mean ash value. This causes the HHV3 difference to be $+1.1 \%$ even if the HHV2 difference were zero. This is approximately what is observed in rows 3 and 4 of Table 8 (e.g. the average difference of the flow minus bomb values for HHV 3 is $1.0 \%$ larger than the average difference of the flow minus bomb values for HHV2).

The difference of the flow minus bomb values for HHV2 completes the evidence for the conclusion, drawn in the previous section, that the new sample division technique provides representative gram-size test samples. The results of this section show that HHV2 is the same for the kilogram-size parent and the gram-size test samples; the results of the previous section showed that gramsize test samples from the same bag were practically the same.

The measurement errors given in the fifth through seventh rows of Table 8 are obtained from the analysis of the flow ash, HHV2, and HHV3 using paired differences from replicate samples $E$ and $E^{\prime}$ for each day. Between-day variability was computed in the usual manner [6]. The precision of a calorimetric 
measurement on kilogram-size samples of dry, processed MSW $(0.4$ to $0.5 \%)$ and on dry cellulose (0.3\%) are comparable in magnitude. Confirmation of the assertion that $E$ and $E^{\prime}$ are replicate samples is obtained from the fact that the measurement error from the flow ash is small.

\subsubsection{Flow Calorimetry of RDF-2}

The flow results on unprocessed MSW (RDF-2) are summarized and compared with those on processed MSW (RDF-4) in Table 9. Results on the unprocessed samples A and then B for each day are given in columns headed "UNPR"; those on the processed samples $E$ and then $E^{\prime}$ for each day are given in columns headed "PR". An analysis of the data in Table 9 is given in Table 10. Average values and imprecisions in the differences of the unprocessed minus processed values for ash, HHV2, and HHV3 are given in the first three rows of Table 10. All differences have $95 \%$ confidence intervals that overlap zero and, thus, are not significantly different from zero (at this confidence level). The average effect of processing kilogram-size samples of RDF-2 to RDF-4 is such as to increase HHV2 by $0.5 \%$ and leave HHV 3 unchanged. The $95 \%$ uncertainty intervals for the HHV2 difference, -3.4 to $+2.4 \%$, and the HHV3 difference, -2.0 to $+2.0 \%$, are larger than those for the differences of the flow minus bomb values given in Table 8 because hand sorting and reconstituting, as we carried it out, did not produce completely identical bags.

Our hand sorting process was subjective because personnel assisting in this task varied and composite materials (e.g. insulated wire or some types of shoes) were not separated into components prior to being assigned a category. Moreover, finer distinctions that might be significant calorimetrically were not made (e.g. distinction between hard and soft plastics or cotton and artificial fiber textiles). It is interesting to note that the day-averages of the percent ash content listed in Table 6 bear the same relation to each other as the total 
Table 9. Flow calorimetry results on unprocessed (UNPR) and processed (PR) MSW.

$$
\text { Ash (Dry Basis), \% }
$$

Day

4

6

7

9

16.97

18.06
$P R(b)$

32.78

32.94

36.17

36.32

26.23

26.11

17.20

17.11
$\mathrm{HHV} 2, \mathrm{MJ} / \mathrm{kg}$

$U N P R(a)$

14.370

14.306

14.838

14.432

14.489

16.725

16.735

18.425

18.295

18.350

18.250
14.458

$\mathrm{HHV} 3, \mathrm{MJ} / \mathrm{kg}$ $U_{N P R}(a) \quad P R^{(b)}$ $21.507 \quad 21.918$ $21.806 \quad 22.126$

$22.570 \quad 22.650$ $23.466 \quad 22.752$

$22.961 \quad 22.671$ $22.418 \quad 22.648$

22.253

$22.272 \quad 22.070$

(a) results for each day are sample $A$ and then $B$.

(b) results for each day are sample $E$ and then $E^{\prime}$. 
Table 10. Analysis of flow calorimetry results on kilogram-size samples of processed and unprocessed MSW.

\section{Unprocessed-Processed}

Property Differences

(Dry Basis)
1) Ash, \%
2) $\mathrm{HHV} 2, \mathrm{MJ} / \mathrm{kg}$
3) $\mathrm{HHV} 3, \mathrm{MJ} / \mathrm{kg}$

$\begin{array}{cc}\text { Average } & \text { Imprecision(a) } \\ +0.36(+1.3 \%)(b) & 1.70(6.0 \%) \\ -0.083(-0.5 \%) & 0.471(2.9 \%) \\ +0.001(+0.0 \%) & 0.446(2.0 \%)\end{array}$

Components of Variability, \$CV

Unprocessed Property (Dry Basis)

Average

Within
Day

Between

Day

4) Ash, \%

28.47

4.9

31.4

5) $\mathrm{HHV} 2, \mathrm{MJ} / \mathrm{kg}$

16.005

0.3

$12 \cdot 3$

6) $\mathrm{HHV} 3, \mathrm{MJ} / \mathrm{kg}$

22.388

1.7

2.3

(a) product of Student $t$ for the $95 \%$ confidence level at 3 degrees of freedom and the standard deviation of the average

(b) percent of average 
percent of nominally noncombustible contents listed in Table 2, line 14 . However, the percent ash content is larger in absolute magnitude than the value given in line 14 by $9.1 \pm 2.4 \%$. This is consistent with the fact that all components of our nominally combustible category produce some ash.

Within-day and between-day components of variability of the data for unprocessed samples are given in rows four to six of Table 10. Comparing these values with the corresponding bomb values listed in Table 5 shows the within-day \% CV for HHV2 and HHV3 are in general agreement.

\subsection{Summary of Statistical Results}

(1) Replicate kilogram-size samples (i.e. samples E and E') of processed MSW (RDF-4) have been prepared for the first time by a new sample division technique.

(2) The differences in the enthalpy of combustion (on a dry basis) of replicate samples $E$ and $E^{\prime}$ provided a $\% C V$ for a single measurement with the new flow calorimeter on an actual sample of RDF of $0.4 \%$. (See Table 8.)

(3) The new sample division technique provided gram-size test samples, from the same kilogram-size parent sample, that have a $\% \mathrm{CV}$ for a single measurement of $0.5 \%$ for the enthalpy of combustion (on a dry basis). (See Table 5.)

(4) The new sample division technique provided gram-size test samples from kilogram-size samples of RDF-4 which have the same average enthalpy of combustion (on a dry basis) as the kilogram-size parent sample to within $0.1 \%$. The 95\% confidence interval for the average difference in the enthalpy of combustion of parent minus gram-size test samples ranges from -1.2 to $+1.0 \%$. (See Table 8 , line 3.)

(5) Processing of kilogram-size samples of MSW having a sieve size of minus $15 \mathrm{~cm}(\mathrm{RDF}-2)$ down to a $2 \mathrm{~mm}$ sieve size (RDF-4) alters the enthalpy of combustion of the material (on a dry basis) by less than $0.5 \%$. The $95 \%$ confidence 
interval for the average difference of the unprocessed minus processed values is from -3.4 to $2.4 \%$. The main contribution to this confidence interval is the variability in the supposed identical samples prepared by hand sorting. (See Table 10.)

(6) Kilogram-size samples of dried RDF-2 having the same enthalpy of combustion (on a dry basis) to about $2 \%$ can be prepared by matching the relative mass compositions according to the following categories of: metals, textiles, plastics, wood/vegetable matter, paper, glass/ceramics, and "fines" (residual grit and sand). (See Tables 5 and 10.)

\section{Discussion and Conclusions}

As indicated in the introduction, this work was performed as part of the effort to resolve the general question of whether or not the calorific value of a multiton quantity of MSW can be obtained by sampling down to one or two grams and obtain representative test samples. This general question can be divided into two parts. The first is: How should one sample a multiton pile or stream of raw waste to obtain a number of kilogram-size increments of sufficient number and amount to characterize the calorific value with a given precision? The second is: How can one obtain representative gram-size test samples that characterize these increments?

The first question is currently being investigated by ASTM Committee $\mathrm{E}-38^{(+)}$and is beyond the scope of this paper.

The sample preparation and measurement protocol of this work were designed

(+) The subject and principles of the design of a sampling protocol, based on experimental test, are addressed in ASTM Method D 2234-76, Standard Method for the collection of a Gross Sample of coal. A variant of this method, as applied to MSW, is under study by the ASTM Committee E- 38 . 
primarily to answer the second question. We assumed that the sample increment was, or could be, conveniently divided into bags containing between 2 and $2.5 \mathrm{~kg}$ of minimally processed MSW (RDF-2). To answer the second question, two problems were studied.

The first problem was the processing problem: Does processing of RDF-2 (MSW of $150 \mathrm{~mm}$ or less particle size) down to RDF-4 (MSW of $2 \mathrm{~mm}$ or less particle size) alter the calorific value of the waste?

The second problem was the kllogram-to-gram sampling problem: How does one obtain a representative gram-size test sample from a kllogram quantity of RDF-4?

Our results show that processing from $150 \mathrm{~mm}$ to $2 \mathrm{~mm}$ particle size does not alter the calorific value of the MSW within the uncertainty of our experiments. The average of the unprocessed minus processed difference in the calorific value on a dry basis is $-0.5 \%$ and on a dry, ash-free basis is $0.0 \%$ of the corresponding mean calorific value. The imprecision in these differences are 2.9 and 2.0\%, respectively of the corresponding mean calorific value. Most of the imprecision is due to the fact that completely identical pairs of samples were not prepared by our hand sorting and reconstituting of RDF-2. An important qualification is that excessive local heating of the RDF-2 during milling was avoided. In our case, powdered dry ice was added to the sample as is it was fed to a Wiley Mill in the final step of processing.

In regards to the kilogram-to-gram sampling problem, our results show that it is possible to obtain gram-size test samples that have the same calorific value as the kilogram parent of RDF-4 if one uses the new sample division technique described in this work. We show that different gram-size test samples taken from a single parent kilogram-size RDF-4 sample have the same calorific value as the parent within the uncertainty of our experiments. The average difference of the parent minus gram-size sample calorific values is $-0.1 \%$ on a 
dry basis and $+0.9 \%$ on a dry, ash-free basis of the corresponding mean calorific value. The imprecisions of the differences are 1.1 and $0.8 \%$, respectively, of the corresponding mean calorifio values.

The new sample division technique was successful because it is insensitive to the effects of segregation whereas our earlier coning and quartering method was not. Because the teohnique employed in this study is time consuming, it is recommended only as a referenoe procedure. An apparatus w1th more rap1d throughput is needed for routine testing. We definitely do not recommend coning and quartering plus taking of grab samples as a technique for the preparation of gram-size test samples of RDF-4. However, it can be used if a within-bag $8 \mathrm{CV}$ in the calorific value (on a dry basis) of three percent or more is tolerable.

In summary, this work shows that if $2.5 \mathrm{~kg}$ increments are collected to characterize the calorific value of a MSW stream, each increment can be processed (provided that excessive local heating is avoided) and then be sampled using the sample division technique cited here (or any other procedure sufficiently insensitive to segregation) to obtain representative gram-size test samples. Combining ${ }^{(+)}$the results on the processing to small particle size (see Table 10) and kilogram-to-gram sampling problem (see Table 8), we show that the average difference in the calorific values of the minimally processed (RDF-2)

(+) Averages of the results on each basis (i.e. dry or dry, ash-free) were obtained by adding; the imprecisions were obtained as the square root of the sum of the squares, 1.e.

$$
\text { Dry: } \quad(-0.5)+(-0.1) \pm \sqrt{(2.9)^{2}+(1.1)^{2}} q
$$

$$
\text { Dry, ash free: } \quad(0.0)+(+0.9) \pm \sqrt{(2.0)^{2}+(0.8)^{2}} \%
$$


kilogram-size sample minus the processed (RDF-4) gram-size sample is $-0.6 \%$ on a $\mathrm{dry}$ basis and $+0.9 \%$ on a dry, ash-free basis of the corresponding mean calorific values. The imprecisions in these values are 3.1 and $2.2 \%$, respectively, of the mean calorific values.

\section{References}

[1] Reilly, M.L., Churney, K.L., Kirklin, D.R., Ledford, A.E., and Domalski, E.S., "An oxygen flow calorimeter for kilogram-size samples of municipal solid waste. Part I. A 25 gram capacity combustion flow calorimeter for determining the calorific value of refuse-derived fuels", Resources and Conservation, $\underline{8}, 147$ (1982).

[2] Domalski, E.S., Churney, K.L., Reilly, M.L., Kirklin, D.R., Ledford, A.E., and Thorton, D.D., "25 gram capacity combustion flow calorimeter", NBSIR 84-2457, U.S. National Bureau of Standards, Washington, D.C. (1982).

[3] Kirklin, D.R., Colbert, J.C., Decker, P.H., Ledford, A.E., Ryan, R.V., and Domalski, E.S., "The variability of municipal solid waste and its relationship to the determination of the calorific value of refuse-derived fuels", Part A of NBSIR 82-2491, U.S. National Bureau of Standards, Washington, D.C. (1982).

[4] Ledford, A.E., Ryan, R.V., Reilly, M.L., Domalski, E.S., and Churney, K.L., "An oxygen flow calorimeter for kilogram-size samples of municipal solid waste. Part II. Trial combustions of kilogram-size samples of municipal solid waste", Resources and Conservation, 8, 159 (1982).

[5] Mandel, J., and Paule, R.C., "Statistical analysis of sampling and measurement errors in the characterization of refuse-derived fuel", Proceedings of the Second International Conference on Materials and Energy from Refuse, Antwerp, Belgium, p6.25 (1981). 
[6] Mandel. J., and Paule, R.C., "Interlaboratory evaluation of a material with unequal numbers of replicates", Analytical Chemlstry, 42:1194 (1970) and Correction, Analytical Chemistry, 43, 1287 (1971).

[7] Kirklin, D.R., Domalski, E.S., Kelly, R.V., and Robbins, C.R., "Ash content and X-ray analysis of selected RDF and coal samples as a function of temperature", Resources and Conservation, 2, 243 (1982).

7. Acknowledgements

Funding for this project was provided by the U. S. Department of Energy (formerly Urban Waste Technology Branch) Office of Renewable Technology, Energy from Municipal Waste Division (during FY 1981, FY 1982, and FY1983) and the NBS Office of Recycled Materials (during FY1981 and FY1982). 
U. S. OEPT, OF COMM.

BIBLIOGRAPHIC DATA

SHEET (See instructions)

4. TITLE AND SUBTITLE

Assessing the Credibility of the Calorific Value of Municipar. Solid Waste

5. AUTHOR(S)

K.L. Churney, E.S. Domal ski, A.E.Ledford, Jr., J.C. Colbert, S.S. Bruce, T.J. Buckley, R.C. Paule. M. L. Rejlly

6. PERFORMING ORGANIZATION (If Jolnt or other thon NBS, see instructions)

MATIONAL BUREAU OF STANDARDS

DEPARTMENT OF COMMERCE

WASHINGTON, D.C. 20234

9. SPONSORING ORGANIZATION NAME AND COMPLETE ADDRESS (Street, City, Stote, ZIP)

7. Contract Grane NoJask Order DE-AI01-76PR06010, A146

U.S. Department of Energy - Office of Renewable Technology,

Energy from Municipal Waste Division - Forrestal Building

1000 Independence Avenue, S.W.

Washington, D.C. 20585

10. SUPPLEMENTARY NOTES

Fundign provided by NBS Office of Recycled Materials (FY1981 and FY1982) and U.S. Department of Energy, Office of Renewable Technology, Energy from Municipal Solid Waste Division (FY1981, FY1982, and FY19832.

$\square$ Document describes a computer program; SF-185. FIPS Software Summary, is attached.

11. ABSTRACT (A 200-word or less factual summary of most significant Informotion. If document Includes o slenlfleant bibliography or. literoture survev, mention it here)

A study has been made at the National Bureau of Standards to establish the limits of reliability of the calorific value of municipal solid waste (MSW) by the bomb calorimetric procedure currently used in commercial test laboratories. This procedure involves using gram-size samples derived from MSW that has been processed down to a particle size of $2 \mathrm{~mm}$ or less. Critics of the procedure argue that gram-size samples are too small to be representative of such a heterogeneous material, and that processing MSh alters its composition.

To test the bomb calorimetric procedure, a $2.5 \mathrm{~kg}$ capacity combustion flow calorimeter was designed and constructed for the determination of the enthalpies of combustion of kilogram-size samples of MSW in flowing oxygen near atmospheric pressure.

Calorimetric data on processed MSW were obtained using both the large flow and a gram-size bomb calorimeter. Intercomparison of results shows that the calorific value (on a dry basis) of gram-size test samples agrees, within the uncertainty of our experiments, with the corresponding values for their kilogram-size parent samples provided that the sample division technique used to obtain the gram-size samples is that described in this work. The average difference of the parent minus gram-size sample values(on a dry basis) is $-0.1 \%$ with an imprecision ( $95 \%$ confidence level) of $+1.1 \%$ of the mean calorific value.

The effects of processing on sample composition were determined by (continued)

12. KEY WORDS (Six to twelve entries; olphabetical order; copitalize only proper names: and separate key words by semicolons) calorimetry; calorific value; enthalpy of combustion; higher heating value, municipal solid waste; refuse derived fuel

13. AVAILABILITY

[X] Unlimited

$\square$ For Official Distribution. Do Not Release to NTIS

Order From Superintendent of Documents, U.S. Government Printing Office, Washington, D.C. 20402.

14. NO. OF PRINTED PAGES

50

15. Price

X] Order From National Technical Information Service (NTIS), Springfield, VA, 22161

$\$ 8.50$ 
intercomparison of flow calorimetric results on kilogram-size samples of processed and minimally processed MSW (150 mm or less particle size) that are nominally identical. The average difference of the unprocessed minus processed values (on a dry basis) is $-0.5 \%$ with an imprecision ( $95 \%$ confidence level) of $\pm 2.9 \%$ of the mean calorific value. 

